\title{
RESEARCH
}

Open Access

\section{On the virulence of two Beauveria bassiana strains against the fall webworm, Hyphantria cunea (Durry) (Lepidoptera: Erebidae), larvae and their biological properties in relation to different abiotic factors}

Ruirui Hu, Penghua Bai, Baosheng Liu* and Jinping Yu

\begin{abstract}
Background: The genus Beauveria is frequently used as a mycoinsecticides in many countries to control insect pests in agriculture, it is being very effective against the fall webworm, Hyphantria cunea (Durry) (Lepidoptera: Erebidae), which is a pest of trees in forests and orchards. Multiple abiotic factors during fungal growth are well known to influence mycelial growth and several physiological adaptations in the conidia produced.

Results: In this study, the pathogenicity of the Beauveria bassiana strains Bb10331 and Bb7725 against $\mathrm{H}$. cunea was evaluated. Peptone potato dextrose agar (PPDA) was used as the medium and colony diameter, conidiation capacity, conidial germination rate were directly affected by relative humidity $(\mathrm{RH})$, illumination, and the ambient

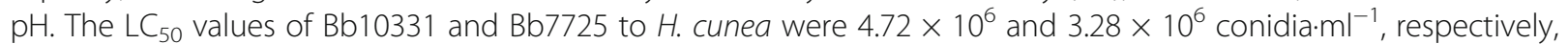
after $120 \mathrm{~h}$ post treatments, while their corresponding $\mathrm{LT}_{50}$ values were 71.13 and $74.54 \mathrm{~h}$ at the concentration of 1 $\times 10^{8}$ conidia/ml. The Bb7725 had a conidial germination rate than did Bb10331 at the same $\mathrm{RH}$. The two strains grew faster under a dark:light (D:L) photoperiod of 12:12 h, and this particular light condition was also most suitable for their conidia production. The optimum $\mathrm{pH}$ for the growth and conidiation of the two strains was approximately 7.0.

Conclusions: Both strains are promising for pest control, possessing effective virulence against $H$. cunea, but this is slightly stronger in Bb7725 than Bb10331. The values of abiotic factors apt to promote the biological properties of each B. bassiana were different.
\end{abstract}

Keywords: Beauveria bassiana, Virulence, Abiotic factors, Hyphantria cunea

\footnotetext{
* Correspondence: 13207529650@163.com

Institute of Plant Protection, Tianjin Academy of Agricultural Sciences, Tianjin,
}

China

(c) The Author(s). 2021 Open Access This article is licensed under a Creative Commons Attribution 4.0 International License, which permits use, sharing, adaptation, distribution and reproduction in any medium or format, as long as you give appropriate credit to the original author(s) and the source, provide a link to the Creative Commons licence, and indicate if changes were made. The images or other third party material in this article are included in the article's Creative Commons licence, unless indicated otherwise in a credit line to the material. If material is not included in the article's Creative Commons licence and your intended use is not permitted by statutory regulation or exceeds the permitted use, you will need to obtain permission directly from the copyright holder. To view a copy of this licence, visit http://creativecommons.org/licenses/by/4.0/. 


\section{Background}

The fall webworm Hyphantria cunea (Durry) (Lepidoptera: Erebidae) has spread widely in China since 1979, when it invaded Liaoning Province, and is now distributed across the provinces of Beijing, Tianjin, Hebei, Shandong, Shanxi, Jiangsu, and Anhui provinces in China (Bai et al. 2020). This caterpillar feeds on leaves of its host plants and overwinters in soil around the damaged trees (Zibaee et al. 2013). Currently, chemical insecticides are still the most commonly used method for controlling $H$. cunea populations and outbreaks (Bi et al. 2018). However, many pesticides have long-term residual effects and also adversely affect natural enemies, as well causing significant environmental pollution (Kim et al. 2020). Therefore, the use of entomopathogens, namely, viruses, fungi, bacteria, protozoa, and nematodes for the biological inhibition of insect pests has become an important tool for pest control (Humber 2016).

Beauveria bassiana is an aerobic pathogenic fungus that parasitizes insect hosts. It has been extensively studied and widely applied in the biological control of agricultural crop and forestry pests as an alternative environment-friendly pest management approach (Kim et al. 2020). This fungus not only infects insects at different life-cycle phases but also exerts lasting sustained effects on the next generation ( $\mathrm{Bi}$ et al. 2018). Host infection by $B$. bassiana occurs via germinating conidia that penetrate the insect's cuticle and reach the hemocoel (Wilson et al. 2017). Environmental factors, including temperature, relative humidity $(\mathrm{RH})$, light, and nutrient composition, can influence the fungal pathogenicity (Padmini and Padmaja 2010). In particular, both temperature and humidity significantly affect the growth, germination, survival, and virulence of such pathogens (Bugeme et al. 2008). Ambient pH influences the activity of some enzymes associated with acidification or alkalization of host tissues in the infection course of plant pathogenic fungi (Prusky and Yacoby 2003). Therefore, biocontrol strategies based on $B$. bassiana do not just depend upon the interaction between host and pathogen but also on the local environmental conditions to which they are exposed (Mishra et al. 2013).

In a previous study, from among 13 strains of $B$. bassiana, two of $B$. bassiana (Bb10331 and Bb7725) were found capable of high virulence against $H$. cunea larvae (Bai et al. 2015). In addition, PPDA medium was deemed as the most suitable medium for the growth of Bb10331 and Bb7725. The effect of temperature on both strains was similar. Their optimum temperature for mycelial growth was $29{ }^{\circ} \mathrm{C}$, and that for conidiation capacity was $26{ }^{\circ} \mathrm{C}$, while that for conidial germination was $26-29^{\circ} \mathrm{C}$.

The present study aimed to evaluate the virulence of those two strains of $B$. bassiana against $H$. cunea larvae, as well the effects of some environmental factors on the biological properties of two strains.

\section{Methods \\ Insect culture}

Pupae of $H$. cunea were obtained from a laboratoryhoused population of $H$. cunea (collected wild moths) at the Chinese Academy of Forestry, Qinghuangdao, in Hebei Province, China. The pupae were maintained in a climate chamber at $25 \pm 1{ }^{\circ} \mathrm{C}$ and an $\mathrm{RH} 50-60 \%$ under a light:dark (L:D) photoperiod of 16:8 h. Plant leaves from Morus alba were provided as a food for the larvae.

\section{Microbial strains and media}

The Bb10331 strain was obtained from the overwintering pupae of $H$. cunea infected with $B$. bassiana in the laboratory. The Bb7725 strain came from the Strain Preservation Center of the Chinese Academy of Forestry.

\section{Virulence of the two strains against Hyphantria cunea}

Fourteen-day-old conidia were used to assay the virulence of the two strains against $H$. cunea larvae infected via feeding. Leaves were separately smeared with $0.35 \mathrm{ml}$ of $1 \times 10^{8}, 1 \times 10^{7}, 1 \times 10^{6}, 1 \times 10^{5}$, and $1 \times 10^{4}$ conidia/ml suspension (treatment) or $0.05 \%$ Tween- 80 (control), and then dried indoors. For each treatment, the Petri dish was first moisturized by adding to it four layers of sterilized filter paper, and the treated leaves were placed inside each dish. A larvicidal bioassay was performed using $20 \mathrm{H}$. cunea larvae (3rd or 4th instars) per treatment. After inoculation with either strain, each batch of the treated larvae was maintained in a large Petri dish for 5 days at $25^{\circ} \mathrm{C}$ and an $\mathrm{RH}$ of $80-90 \%$, and monitored daily to record mortality. The fungal virulence to the larvae of each strain was analyzed in terms of a corrected mortality rate. The median lethal concentration $\left(\mathrm{LC}_{50}\right)$ after $120 \mathrm{~h}$ of treatments was calculated. The median lethal time, $\mathrm{LT}_{50}$, was estimated using leaves that were smeared with $0.35 \mathrm{ml}$ of the $1 \times 10^{8}$ conidia/ $\mathrm{ml}$ suspension. The bioassay of each type was repeated 3 times.

$$
\begin{aligned}
& \text { Corrected mortality rate }(\%) \\
& =\left(\frac{\text { mortality in treatment-mortality in control }}{1-\text { mortality in control }}\right) \\
& \quad \times 100
\end{aligned}
$$

\section{Effects of abiotic factors on the biological properties of the two fungal strains}

Colony disks were placed on PPDA medium and cultured in an incubator at different $\operatorname{HR}(75,85,90,95$, and 100\%), different light conditions: full dark (0 L:24 D), 12 h light (12 L:12 D), and full light (24 L:0 D), and 
different $\mathrm{pH}$ levels (5.0-9.0), respectively. Each temperature was replicated three times. The biological performance of each of the two strains was evaluated. For the full dark treatments, the Petri dishes were maintained in the same incubator those for the white light treatments, but inside a plastic box with ventilation holes that was covered with a thick black cloth sleeve.

\section{Assays for biological properties}

A medium ( $2 \%$ sucrose and $0.5 \%$ peptone) was used to quantify the conidial germination rate of each treatment at 6,12 , and $24 \mathrm{~h}$. Their conidia were observed three times per replicate, with approximately 100 conidiation events observed in total. Colony growth rates were evaluated by measuring the diameters of different treatments on day 3,6 , and 10 , respectively. Each treatment was repeated 5 times. After 14 days of incubation at $25{ }^{\circ} \mathrm{C}$ and $12 \mathrm{~L}: 12 \mathrm{D}$, three colony disks $(\phi=5 \mathrm{~mm})$ at the same position from the center of the Petri plates were bored with a cork borer. Conidia on each disk were then gently brushed off into $20 \mathrm{ml}$ of $0.05 \%$ Tween- 80 via vortex. The conidial concentration in the suspension was determined using a hemocytometer and converted to the number of conidia per square centimeter culture. Each treatment was repeated thrice (Zhu et al. 2016).

\section{Data analysis}

Mortality data were corrected using the control group mortality, using Excel. The $\mathrm{LC}_{50}$ and $\mathrm{LT}_{50}$, correlation coefficient $(R)$, and $95 \%$ confidence interval values of virulence regression equations were calculated by SPSS (v22.0)

\section{Results}

\section{Virulence of the two strains to Hyphantria cunea}

The virulence of Bb10331 and Bb7725 strains against $H$. cunea was evinced by their corresponding $\mathrm{LC}_{50}$ and $\mathrm{LT}_{50}$ values of the 2 strains. The relative difference in the $\mathrm{LC}_{50}$ and $\mathrm{LT}_{50}$ values between the two strains were $1.44 \times 10^{6}$ conidia $\cdot \mathrm{ml}^{-1}$ and $3.41 \mathrm{~h}$, respectively (Table 1 ).

\section{Effect of relative humidity on biological properties of the two fungal strains}

The conidial germination rate of the two strains under differing RH was fitted by a curve. As illustrated in Fig. 1, the conidia germination rate of Bb7725 exceeds that of
Bb10331, and both germinations' rate increased with an increasing $\mathrm{RH}$. The curve equations of Bb7725 and Bb10331 strains were $y=-0.040 x^{2}+7.487 x-258.8\left(R^{2}=\right.$ $0.984)$ and $y=-0.036 x^{2}+6.880 x-238.9\left(R^{2}=0.982\right)$, respectively (Fig. 1).

\section{Effect of illumination on biological properties of the two fungal strains}

The Bb10331 strain always maintained high values for colony diameter and conidiation capacity than Bb7725, except on the 3rd day (Fig. 2). The colony diameter of either strain was maximal at $\mathrm{D}: \mathrm{L}=12: 12 \mathrm{~h}$. After $24 \mathrm{~h}$ of culturing, the conidial germination rates of both strains were the highest in the dark, but after $48 \mathrm{~h}$, they had generally increased significantly. The conidial germination rate of Bb7725 strain reached $100 \%$ at three illumination conditions (Figs. 2 and 3).

Table 2 shows that mycelium produced more conidiation under a full light regime. In general, Bb7725 had lower values for the conidial germination rate than Bb10331. The conidiation capacity of the two strains at $\mathrm{D}: \mathrm{L}=12: 12 \mathrm{~h}$ and full light was significantly higher $(P<$ 0.05) than that in full dark (Table 3).

\section{Effect of $\mathrm{pH}$ on biological properties of two strains}

As Fig. 3 shows, the colony diameter of either strain increased at first and then decreased as the $\mathrm{pH}$ increased. The colony diameter of Bb7725 (48.94 $\mathrm{mm})$ peaked at $\mathrm{pH}=6.0$, while of $\mathrm{Bb} 10331$, it was the largest $(43.77$ $\mathrm{mm})$ at $\mathrm{pH}=6.5$. The curve equations of Bb7725 and Bb10331 strains were $y=-2.903 x^{2}+40.65 x-93.53\left(R^{2}=\right.$ $0.639)$ and $y=-2.293 x^{2}+32.52 x-71.79\left(R^{2}=0.860\right)$, respectively (Fig. 4). The maximum conidiation capacity was observed at $\mathrm{pH}=7.0$. The conidiation capacity at $\mathrm{pH}=9$ was significantly lower than that at other $\mathrm{pH}$ values. As the $\mathrm{pH}$ value increased, the conidia germination rate evidently decreased. The conidial germination rate was greatest at $\mathrm{pH} 5.5 \sim 6.0$, reaching 90.14 91.27\%, and they were significantly higher than the conidial germination at other $\mathrm{pH}$ values.

\section{Discussion}

The genus Beauveria is often used as a mycoinsecticides in many countries to control insect pests in agriculture. The conidia of entomopathogenic fungi (EPF) must retain high viability and virulence for effective biological

Table 1 Virulence of Bb10331 and Bb7725 to Hyphantria cunea

\begin{tabular}{|c|c|c|c|c|}
\hline \multirow[t]{2}{*}{ Strain } & \multicolumn{2}{|c|}{ Median lethal concentration after $120 \mathrm{~h}$} & \multicolumn{2}{|c|}{ Median lethal time at $1 \times 10^{8}{\text { conidia } \cdot \mathrm{ml}^{-1}}^{-1}$} \\
\hline & $\mathrm{LC}_{50}(95 \% \mathrm{Cl}) / \times 10^{6}{\text { conidia } \cdot \mathrm{ml}^{-1}}^{-1}$ & Correlation coefficient & $\mathrm{LT}_{50}(95 \% \mathrm{Cl}) / \mathrm{h}$ & Correlation coefficient \\
\hline $\mathrm{Bb}-10331$ & $4.72(2.46 \sim 10.67)$ & 0.9884 & $74.54(69.11 \sim 80.61)$ & 0.9732 \\
\hline Bb-7725 & $3.28(1.76 \sim 6.88)$ & 0.9749 & $71.13(65.96 \sim 76.66)$ & 0.9749 \\
\hline
\end{tabular}

$\mathrm{LC}_{50}$ and $\mathrm{LT}_{50}$ refer to median lethal concentration and median lethal time, respectively

The $95 \%$ confidence intervals $(\mathrm{Cl})$ were calculated by delta method that accounts for asymptotic relationships 


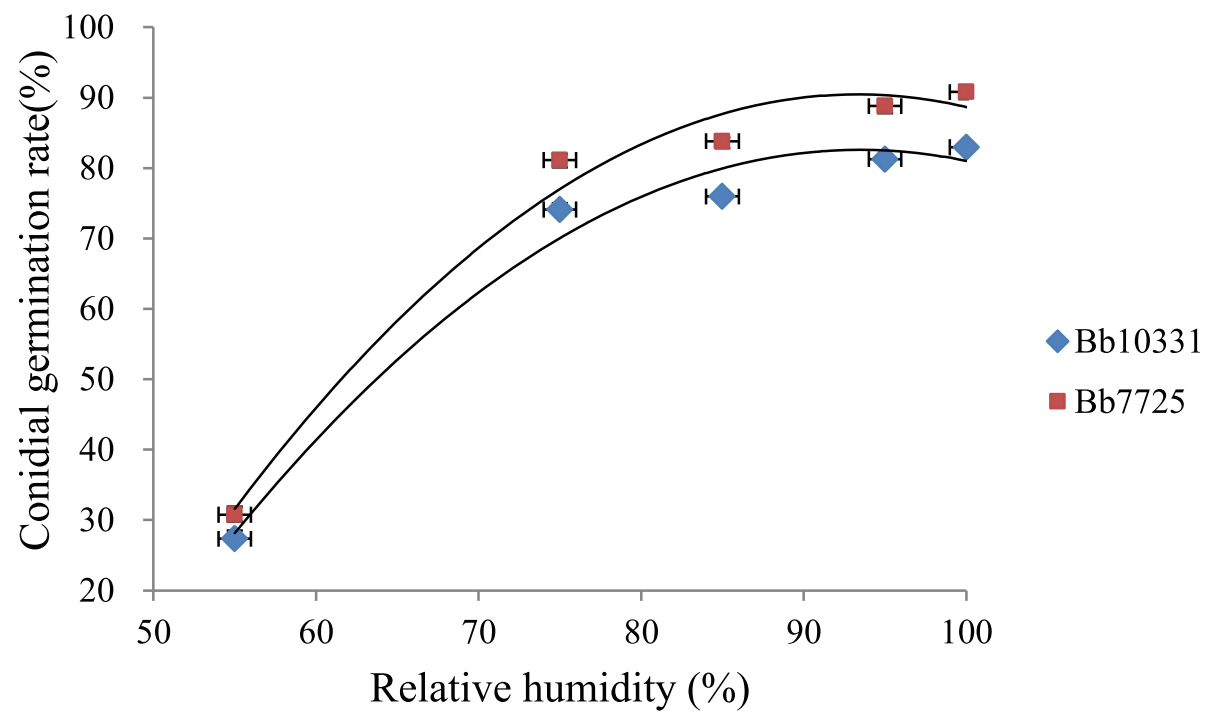

Fig. 1 Conidial germination rate at different relative humidity

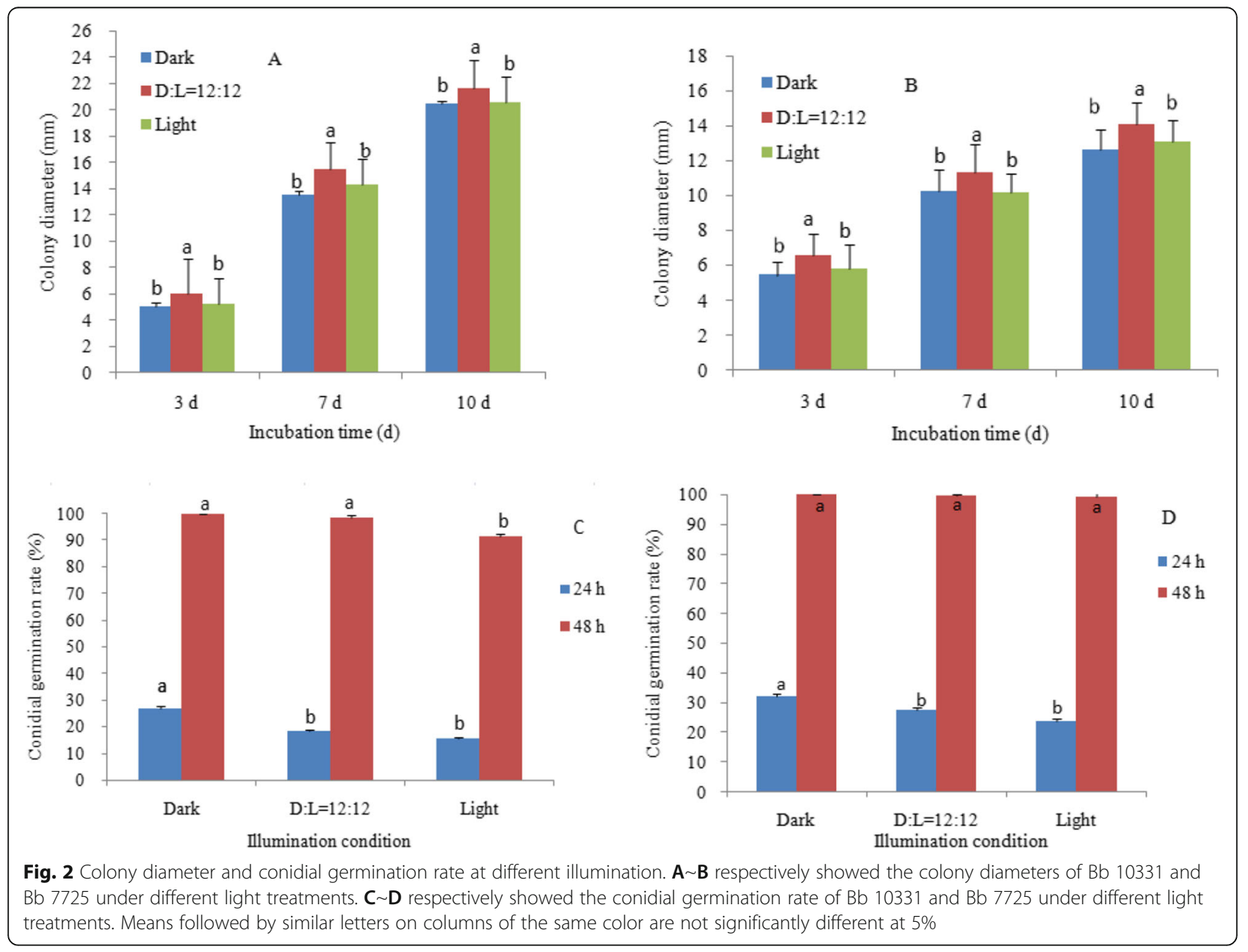




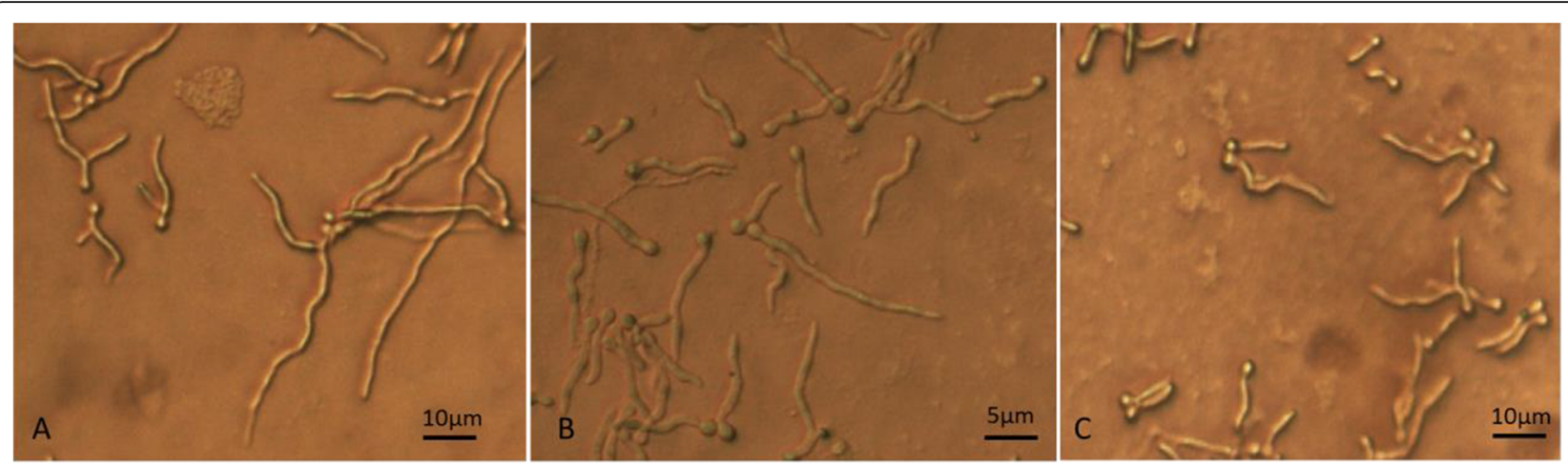

Fig. 3 Conidial germination rate of the Bb7725 strain under different light conditions at 48 h A full light (20x); B dark: light photoperiod of $12: 12$ h (40x), and C full dark (20x)

control to ensue (Hong et al. 2002). Biocontrol strategies based on entomopathogenic fungi are not only dependent upon the interaction between host and pathogen but also on the environment to which they are exposed (Mishra et al. 2013). In this study, two B. bassiana strains differed somewhat in their virulence against $H$. cunea, which might be related to their biological properties. Multiple abiotic factors were shown capable of influencing conidiation in Bb10331 and Bb7725, including the medium type, carbon to nitrogen ratio, and the temperature. The two strains' colony diameter, conidiation capacity, and their conidia germination rate were directly impacted by $\mathrm{RH}$, illumination regime, and ambient $\mathrm{pH}$.

Humidity is one of the most important environmental factors affecting the survival and activity of entomopathogenic fungi (Bugti et al. 2020). Not only concentration it affect fungal germination, it is also essential for EPF infection and subsequent sporulation on insect cadavers (Mishra et al. 2013). Early work by Ferron (1977) demonstrated that $92 \% \mathrm{RH}$ is required for B. bassiana to get conidial germination in the absence of the host. However, in this study, when $\mathrm{RH}$ is $70 \%$, the conidial germination rate of both strains could surpass $70 \%$. That is to say, the relative humidity required for conidial germination of different fungal strains varies among them. In addition, the infection potential of EPF also depends upon the exposure time to favorable humidity conditions, given the positive correlation between them (Fargues and Luz 2000). Our results indicated

Table 2 The conidiation capacity of Bb10331 and Bb7725 at different illumination

\begin{tabular}{|c|c|c|c|}
\hline \multirow[t]{2}{*}{ Isolate } & \multicolumn{3}{|c|}{ Conidiation capacity $/ \times 10^{6}$ conidia $\cdot \mathrm{ml}^{-1}$} \\
\hline & Dark & $\mathrm{D}: \mathrm{L}=12: 12$ & Full light \\
\hline Bb10331 & $0.35 \pm 0.06 b$ & $0.67 \pm 0.06 a$ & $0.73 \pm 0.05 a$ \\
\hline Bb7725 & $0.06 \pm 0.01 b$ & $0.23 \pm 0.03 a$ & $0.24 \pm 0.03 \mathrm{a}$ \\
\hline
\end{tabular}

The number after \pm is standard deviation. Means followed by similar letters in a column are not significantly different at $5 \%$ that the optimum $\mathrm{RH}$ for the Bb10331 and Bb7725 strains was $95-100 \%$. However, it is necessary to further compare the infection of these two strains against $H$. cunea at different $\mathrm{RH}$ levels in subsequent studies.

Illumination is one of the many signals that fungi use to perceive and to interact with their environment, providing them with critical information about their habitat (Corrochano 2007). Many studies have shown that illumination regimes have conspicuous effects on mycelial growth, conidial germination, and conidiation capacity (Fanelli et al. 2012; Dias et al. 2019). Fungal species can exhibit differential responses to light; for example, fungi sense light to protect themselves against DNA damage caused by certain color or solar ultraviolet wavelengths, by timing the release of spores or by inducing enhanced tolerance to stress for better physiological adaptation (Chelico and Khachatourians 2008; Braga et al. 2015). In the present study, the mycelium produced more conidia under light than dark conditions. This result is consistent with that of Dias et al. (2019). Although Bb10331's colony diameter and conidiation capacity surpassed Bb7725's, it had a lower conidial germination rate. This result suggests that Bb7725 has a higher effective conidia capacity. The phytochrome gene deletion in a strain of the insect pathogen B. bassiana generated higher osmosensitivity, an increased antioxidant capability, and weakened conidial thermotolerance (Qiu et al. 2014). Accordingly, the mycelial growth, conidiation capacity, and conidial germination rate of the two strains studied here differed under the same light treatment, likely due to their differential expression of phytochrome genes. Crucially, the lethal ability of either strain against $H$. cunea depends on their number of germinated conidia. Finally, the colors and types of light can also play an important role in the biological characteristics of $B$. bassiana strains (Yu et al. 2013; Qiu et al. 2014).

Ambient $\mathrm{pH}$ is an environmental stimulus capable of inducing a series of physiological and cellular events in 
Table 3 The conidiation capacity and conidia germination rate of 2 strains

\begin{tabular}{|c|c|c|c|c|}
\hline \multirow[t]{2}{*}{ pH value } & \multicolumn{2}{|c|}{ Conidiation capacity $\left(\times 10^{8}{\left.\text { conidia} \cdot \mathrm{ml}^{-1}\right)}^{-1}\right.$} & \multicolumn{2}{|c|}{ Conidia germination rate (\%) } \\
\hline & Bb10331 & Bb7725 & Bb10331 & Bb7725 \\
\hline 5.0 & $2.17 \pm 0.23 d$ & $0.47 \pm 0.11 d$ & $79.71 \pm 1.34 b$ & $81.60 \pm 1.57 b$ \\
\hline 5.5 & $2.28 \pm 0.33 \mathrm{bcd}$ & $1.23 \pm 0.20 b c$ & $89.45 \pm 2.87 \mathrm{a}$ & $91.27 \pm 2.60 \mathrm{a}$ \\
\hline 6.0 & $2.40 \pm 0.23 \mathrm{bcd}$ & $1.75 \pm 0.22 b c$ & $88.28 \pm 1.83 \mathrm{a}$ & $90.14 \pm 1.81 \mathrm{a}$ \\
\hline 6.5 & $3.14 \pm 0.32 \mathrm{ab}$ & $2.47 \pm 0.29 a$ & $83.14 \pm 1.06 b$ & $83.98 \pm 1.56 b$ \\
\hline 7.0 & $3.69 \pm 0.33 a$ & $2.37 \pm 0.25 \mathrm{a}$ & $80.23 \pm 1.20 \mathrm{~b}$ & $81.27 \pm 1.55 b$ \\
\hline 7.5 & $2.79 \pm 0.27 b c$ & $1.84 \pm 0.09 b$ & $73.14 \pm 1.72 c$ & $75.11 \pm 1.32 c$ \\
\hline 8.0 & $2.70 \pm 0.29 \mathrm{bcd}$ & $1.50 \pm 0.22 b c$ & $53.04 \pm 1.18 d$ & $63.34 \pm 1.76 \mathrm{~d}$ \\
\hline 9.0 & $1.45 \pm 0.12 \mathrm{e}$ & $1.23 \pm 0.27 c$ & $3.84 \pm 0.23 \mathrm{e}$ & $6.61 \pm 0.69 \mathrm{e}$ \\
\hline
\end{tabular}

The number after \pm is standard deviation. Means followed by similar letters in a column are not significantly different at $5 \%$

microorganisms. Fungal adaptation to ambient $\mathrm{pH}$ relies on homeostasis of intracellular $\mathrm{pH}$ and the proper expression of permeases, secreted proteases, toxins, and antibiotics (Zhu et al. 2016). Work by Zhu et al. (2016) also confirmed that $\mathrm{PacC}$ and Pal partners regulate the growth and conidiation of $B$. bassiana in a $\mathrm{pH}$ dependent manner and highlighted their importance for this fungal response to $\mathrm{pH}$. Furthermore, $\mathrm{pH}$ variously affects different species of fungi; for example, the ambient $\mathrm{pH}$ has a major regulatory influence on conidiation in these species of Trichoderma atroviride and T. hamatum, whose conidiation and growth are favored by low pH (Steyaert et al. 2010). By contrast, in our study, the colony diameter and conidiation of both strains tended to increase initially but then diminished with a higher $\mathrm{pH}$; this proves that their conidiation as well as growth are favored by a neutral $\mathrm{pH}$. It has been speculated that the strong alkaline conditions may foster the production of fragmented vacuoles in hyphal cells, inducing high osmosensitivity in these cells (Antonio et al. 2010).
Moreover, the responsive genes involved in various cellular events, such as growth, ion tolerance, cell differentiation, cell wall remodeling, secondary metabolism, and host infection are expressed under suitable $\mathrm{pH}$ conditions (Merhej et al. 2011; Cornet and Gaillardin 2014; O’Meara et al. 2014).

\section{Conclusion}

It is important to identify abiotic factors conferring optimal biological properties of different strains, as they directly affect their virulence against target pests. Although both Bb10331 and Bb7725 exhibit robust virulence against $H$. cunea, the virulence of $\mathrm{Bb} 7725$ is slightly stronger than that of Bb10331. Furthermore, the values of abiotic factors for attaining the most suitable biological properties of each $B$. bassiana were different. These two promising strains should now be tested under field conditions to confirm their virulence against $H$. cunea.

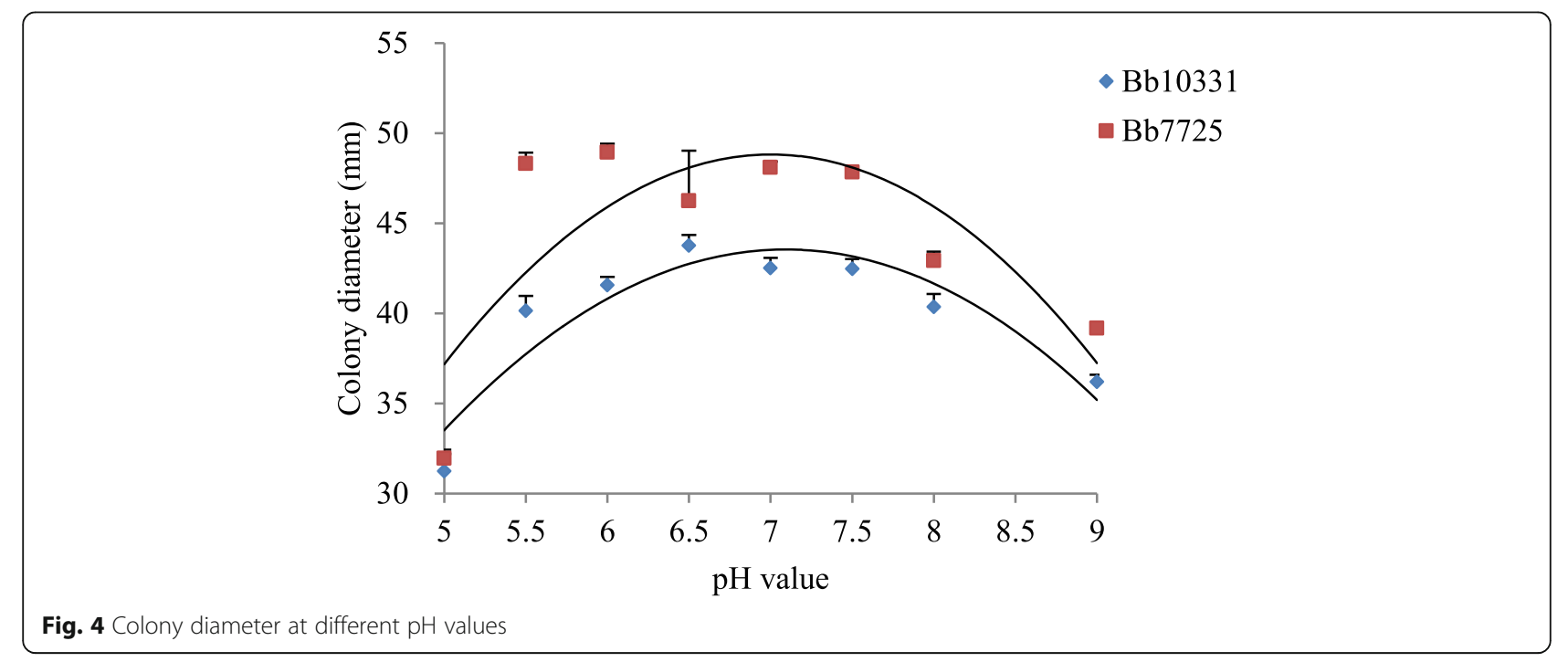




\section{Abbreviations}

Bb: Beauveria bassiana; PPDA: Peptone potato dextrose agar; Cl: Confidence intervals; LC: Lethal concentration; LT: Lethal time

\section{Acknowledgements}

We thank Xishu Gu, WeihongXu, and Shuqin Sun for their help with collecting and handling the large datasets.

\section{Authors' contributions}

BSL conceived and designed the experiments; RRH and PHB performed the experiments and conducted the data analyses; JPY conducted the data analyses. All authors have read and approved the manuscript.

\section{Funding}

This research was funded by Research and Integrated Demonstration on Ecological Control Technology of Main Poplar Diseases (12ZCZDNC00500), the Creative Research for Young Scientists of Tianjin Academy of Agricultural Sciences (2020008), Agricultural Transformation of Scientific and Technological Achievements of Tianjin: Introduction and Demonstration of sex pheromone Synergist of Hyphantria cunea (201901070)

\section{Availability of data and materials}

The datasets used and/or analyzed during the current study are available from the corresponding author on reasonable request.

\section{Declarations}

Ethics approval and consent to participate

Not applicable.

\section{Consent for publication}

Not applicable.

\section{Competing interests}

There is no conflict of interest.

\section{Received: 28 February 2021 Accepted: 11 July 2021}

Published online: 21 July 2021

\section{References}

Antonio CCJ, Lucila OC, Miriam TS, Scott G, José RH (2010) Functional analysis of the $\mathrm{pH}$ responsive pathway $\mathrm{Pal} / \mathrm{Rim}$ in the phytopathogenic basidiomycete Ustilago maydis. Fungal Genet Biol 47(5):446-457. https://doi.org/10.1016/j. fgb.2010.02.004

Bai PH, Bai YC, Feng YR, Liu BS (2015) Pathogenicity and field application of different strains of Beauveria bassiana on larvae of Hyphantria cunea Drury. J Tianjin Norm U 35:112-115

Bai PH, Wang HM, Liu BS, Li M, Tang R (2020) Botanical volatiles selection in mediating electrophysiological responses and reproductive behaviors for the fall webworm moth Hyphantria cunea. Front Physiol 11:1-10

Bi YG, Qin QL, Wang ZG, Zhang JH, Guo XJ, Liu HF (2018) An auto-contamination trap-strips system for biological control of Hyphantria cunea (Lepidoptera: Arctiidae), an invasive pest in china. Int J Pest Manage 64:230-235

Braga GUL, Rangel DEN, Fernandes ÉKK, Flint SD, Roberts DW (2015) Molecular and physiological effects of environmental UV radiation on fungal conidia. Curr Genet 61(3):405-425. https://doi.org/10.1007/s00294-015-0483-0

Bugeme DM, Maniania NK, Knapp M, Boga HI (2008) Effect of temperature on virulence of Beauveria bassiana and Metarhizium anisopliae isolates to Tetranychus evansi. Exp Appl Acarol 46(1-4):275-285. https://doi.org/10.1007/ s10493-008-9179-1

Bugti GA, Na C, Feng LH, Bin W (2020) Field bioassay assessment of entomopathogenic fungi on Aphis gossypii (Glover). J Entomol 17:20-26

Chelico L, Khachatourians GG (2008) Isolation and characterization of nucleotide excision repair deficient mutants of the entomopathogenic fungus, Beauveria bassiana. J Invertebr Pathol 98:3-100

Cornet M, Gaillardin C (2014) pH signaling in human fungal pathogens: a new target for antifungal strategies. Eukaryot Cell 13(3):342-352. https://doi.org/1 0.1128/EC.00313-13

Corrochano LM (2007) Fungal photoreceptors: sensory molecules for fungal development and behaviour. Photochem Photobiol Sci 6(7):725-736. https:// doi.org/10.1039/b702155k
Dias LP, Nicolás P, Braga GUL, Ferreira PC, Rangel DEN (2019) Outcome of blue, green, red, and white light on Metarhizium robertsii during mycelial growth on conidial stress tolerance and gene expression. Fungal Biol 124(5):263-272. https://doi.org/10.1016/j.funbio.2019.04.007

Fanelli F, Schmidt-Heydt M, Haidukowski M, Susca A, Geisen R, Logrieco A, Mule $\mathrm{G}$ (2012) Influence of light on growth, conidiation and fumonisin production by Fusarium verticillioides. Fungal Biol 116(2):241-248. https://doi.org/10.1016/ j.funbio.2011.11.007

Fargues J, Luz C (2000) Effects of fluctuating moisture and temperature regimes on the infection potential of Beauveria bassiana for Rhodnius prolixus. J Invertebr Pathol 75(3):202-211. https://doi.org/10.1006/jipa.1999.4923

Ferron P (1977) Influence of relative humidity on the development of fungal infection caused by Beauveria bassiuna (fungi imperfecta monitales) in imagines of Acanthoscefides obtectus (Cal.:Bruchidae). Entomophaga 2:393396

Hong TD, Ellis RH, Gunn J, Moore D (2002) Relative humidity, temperature, and the equilibrium moisture content of conidia of Beauveria bassiana (Balsamo) Vuillemin: a quantitative approach. J Stored Prod Res 38(1):33-41. https://doi. org/10.1016/S0022-474X(00)00043-6

Humber RA (2016) Seeking stability for research and applied uses of entomopathogenic fungi as biological control agents. J Asia Pac Entomol 19(4):1019-1025. https://doi.org/10.1016/j.aspen.2016.09.006

Kim S, Kim JC, Lee SJ, Lee MR, Park SU, Li DW, Baek S, Shin TA, Kin JS (2020) Beauveria bassiana ERL-836 and JEF-007 with similar virulence show different gene expression when interacting with cuticles of western flower thrips, Frankniella occidentalis. BMC Genomics 21:1-12

Merhej J, Richard-Forget F, Barreau C (2011) The pH regulatory factor Pac1 regulates Tri gene expression and trichothecene production in Fusarium graminearum. Fungal Genet Biol 48(3):275-284. https://doi.org/10.1016/j.fgb.2 010.11 .008

Mishra S, Kumar P, Malik A (2013) Effect of temperature and humidity on pathogenicity of native Beauveria bassiana isolate against Musca domestica $\mathrm{L}$. J Parasitic Dis 39:697

O'Meara TR, Xu WJ, Selvig KM, O'Meara MJ, Mitchell AP, Alspaugh JA (2014) The Cryptococcus neoformans Rim 101 transcription factor directly regulates genes required for adaption to the host. Mol Cell Biol 34(4):673-684. https:// doi.org/10.1128/MCB.01359-13

Padmini PCP, Padmaja V (2010) Impact of different relative humidity on in vitro growth and sporulation of entomopathogenic fungal isolates of Beauveria species. Int J Pharm Biol Sci Arch 1:355-359

Prusky D, Yacoby N (2003) Pathogenic fungi: leading or led by ambient $\mathrm{pH}$ ? Mol Plant Pathol 4(6):509-516. https://doi.org/10.1046/j.1364-3703.2003.00196.x

Qiu L, Wang JJ, Chu ZJ, Ying SH, Feng MG (2014) Phytochrome controlsconidiation in response to red light and daylight length and regulates multistress tolerance in Beauveria bassiana. Environ Microbiol 16(7):2316-2328. https:// doi.org/10.1111/1462-2920.12486

Steyaert JM, Weld RJ, Stewart A (2010) Ambient pH intrinsically influences Trichoderma conidiation and colony morphology. Fungal Biol 114(2-3):198208. https://doi.org/10.1016/j.funbio.2009.12.004

Wilson WM, Ibarra JE, Oropeza A, Hernández MA, Toledo-Hernández RA, Toledo J (2017) Infection of Anastrepha ludens (Diptera: Tephritidae) adults during emergence from soil treated with Beauveria bassiana under various texture, humidity, and temperature conditions. Fla Entomol 100(3):503-508. https:// doi.org/10.1653/024.100.0302

Yu SM, Ramkumar G, Lee YH (2013) Light quality influences the virulence and physiological responses of Colletotrichum acutatum causing anthracnose in pepper plants. J Appl Microbiol 115(2):509-516. https://doi.org/10.1111/ja m.12252

Zhu J, Ying SH, Feng MG (2016) The Pal pathway required for ambient pH adaptation regulates growth, conidiation, and osmotolerance of Beauveria bassiana in a pH-dependent manner. Appl Microbiol Biotechnol 12:1-11

Zibaee I, Bandani AR, Sendi JJ (2013) Pathogenicity of Beauveria bassiana to fall webworm (Hyphantria cunea) (Lepidoptera: Erebidae) on different host plants. Plant Protect Sci 49(4):169-176. https://doi.org/10.17221/72/2012-PPS

\section{Publisher's Note}

Springer Nature remains neutral with regard to jurisdictional claims in published maps and institutional affiliations. 